\title{
Differentiation of Isomeric Compounds by Two-Stage Proton Transfer Reaction Time-of-Flight Mass Spectrometry
}

\author{
Satoshi Inomata and Hiroshi Tanimoto \\ National Institute for Environmental Studies, Tsukuba, Japan
}

We investigated a two-stage ion source for proton transfer reaction (PTR) ionization to achieve more selective mass spectrometric (MS) detection of selected volatile organic compounds (VOCs) than that achieved with commonly used PTR-MS instruments, which are based on single-step PTR ionization with $\mathrm{H}_{3} \mathrm{O}^{+}$. The two-stage PTR ion source generated reagent ions other than $\mathrm{H}_{3} \mathrm{O}^{+}$by an initial PTR between $\mathrm{H}_{3} \mathrm{O}^{+}$and a selected VOC, and then a second PTR ionization occurred only for VOCs with proton affinities larger than the affinity of the reagent VOC. Acetone and acetonitrile were useful as reagent VOCs because they provided dominant peaks as a protonated form. Using two-stage PTR-MS, we differentiated isomeric VOCs (for example, ethyl acetate and 1,4-dioxane) by means of differences in their proton affinities; protonated acetone formed the $[\mathrm{M}+\mathrm{H}]^{+}$ion from ethyl acetate but not from 1,4-dioxane. The PTR-MS-derived concentrations agreed quantitatively with those independently determined by Fourier transform infrared spectroscopy (FT-IR) at parts per million by volume (ppmv) levels. In addition, interfering fragment ions formed from alkyl benzenes at $\mathrm{m} / \mathrm{z} 79\left(\mathrm{C}_{6} \mathrm{H}_{7}{ }^{+}\right)$ could be distinguished from the $\mathrm{m} / \mathrm{z} 79$ ion arising from protonation of benzene, and therefore this method would prevent overestimation of benzene concentrations in air samples in which both benzene and alkyl benzenes are present. This two-stage PTR ionization may be useful for distinguishing various isomeric species, including aldehydes and ketones, if appropriate reagent ions are selected. (J Am Soc Mass Spectrom 2008, 19, 325-331) (c) 2008 American Society for Mass Spectrometry

$\mathrm{P}$ roton transfer reaction mass spectrometry (PTRMS) is widely used for the rapid and sensitive determination of trace amounts of volatile organic compounds (VOCs) in air [1-3]. PTR ionization is a type of chemical ionization (CI) [4] that permits soft ionization of chemical species that have proton affinities (PAs) greater than that of the reagent species. The hydronium ion $\left(\mathrm{H}_{3} \mathrm{O}^{+}\right)$is commonly used as a primary ion because it undergoes PTRs with most VOCs but not with the major components of the atmosphere (such as $\mathrm{N}_{2}, \mathrm{O}_{2}$, and $\mathrm{CO}_{2}$ ). If an appropriate reagent ion other than $\mathrm{H}_{3} \mathrm{O}^{+}$is chosen for PTR ionization, designated chemical species can be detected selectively [3]. However, little research has been done on this technique, probably because few methods are available for the selective production of other reagent ions.

Reagent ions such as $\left(\mathrm{C}_{2} \mathrm{H}_{5} \mathrm{OH}\right)_{n} \cdot \mathrm{H}^{+}$and $\left(\mathrm{CH}_{3} \mathrm{COCH}_{3}\right)_{2} \cdot \mathrm{H}^{+}$have been used for the detection of ammonia in air by chemical ionization mass spectrometry (CI-MS) [5-7]. $\left(\mathrm{C}_{2} \mathrm{H}_{5} \mathrm{OH}\right)_{n} \cdot \mathrm{H}^{+}$and $\left(\mathrm{CH}_{3} \mathrm{COCH}_{3}\right)_{2} \cdot \mathrm{H}^{+}$ions were generated in radioactive ion sources from ethanol $\left(\mathrm{C}_{2} \mathrm{H}_{5} \mathrm{OH}\right)$ and acetone $\left(\mathrm{CH}_{3} \mathrm{COCH}_{3}\right)$, respectively, diluted in $\mathrm{N}_{2}$. Because flow tube reactors were used, the

Address reprint requests to Dr. S. Inomata, Atmospheric Environment Division, National Institute for Environmental Studies, 16-2, Onogawa, Tsukuba, Ibaraki 305-8506, Japan. E-mail: ino@nies.go.jp predominant primary ions were cluster ions. Ammonia was ionized not only by the PTR, which generated $\mathrm{NH}_{4}{ }^{+}$, but also by $\mathrm{CI}$, which produced cluster ions such as $\mathrm{C}_{2} \mathrm{H}_{5} \mathrm{OH} \cdot \mathrm{NH}_{4}{ }^{+}$and $\left(\mathrm{CH}_{3} \mathrm{COCH}_{3}\right)_{2} \cdot \mathrm{NH}_{4}{ }^{+}$; as a result, the interpretation of the resulting mass spectra was often complicated.

In this study, we developed a new ion source for PTR-MS in which designated reagent ions other than $\mathrm{H}_{3} \mathrm{O}^{+}$are produced through protonation by $\mathrm{H}_{3} \mathrm{O}^{+}$ions. In the first stage, PTR between $\mathrm{H}_{3} \mathrm{O}^{+}$and a designated VOC $\left(\mathrm{VOC}_{1}\right)$ selectively produces reagent ions $\mathrm{VOC}_{1} \cdot \mathrm{H}^{+}$; when a second $\mathrm{VOC}\left(\mathrm{VOC}_{2}\right)$ with a PA larger than that of $\mathrm{VOC}_{1}$ is present in a sample, a second PTR ionization occurs to produce $\mathrm{VOC}_{2} \cdot \mathrm{H}^{+}$ions:

$$
\begin{aligned}
& \mathrm{H}_{3} \mathrm{O}^{+}+\mathrm{VOC}_{1} \rightarrow \mathrm{VOC}_{1} \cdot \mathrm{H}^{+}+\mathrm{H}_{2} \mathrm{O} \\
& \mathrm{VOC}_{1} \mathrm{H}^{+}+\mathrm{VOC}_{2} \rightarrow \mathrm{VOC}_{2} \cdot \mathrm{H}^{+}+\mathrm{VOC}_{1}
\end{aligned}
$$

Note that soft ionization is used for the production of the reagent ion, as well as for the ionization of the VOCs in the sample. The performance of this ion source was tested with several $\mathrm{VOC}_{1}$ candidates. The ion source was used to differentiate isomeric VOCs $\left(V C_{2}\right)$; we identified the isomeric VOCs from the mass signals of their parent ions (i.e., the protonated VOCs). Therefore, this technique is unlike the collision-induced dissocia- 
Table 1. Primary product ions for two-stage PTR with several reagent VOCs

\begin{tabular}{|c|c|c|c|c|}
\hline $\mathrm{VOC}_{1}(\mathrm{M})$ & $\mathrm{CH}_{3} \mathrm{CN}$ & $\mathrm{C}_{6} \mathrm{H}_{5} \mathrm{CH}_{3}$ & $\left(\mathrm{CH}_{3}\right)_{2} \mathrm{CO}$ & $\left(\mathrm{C}_{2} \mathrm{H}_{5}\right)_{2} \mathrm{CO}$ \\
\hline $\mathrm{PA}\left(\mathrm{kJ} \mathrm{mol} \mathrm{mol}^{-1}\right)^{\mathrm{a}}$ & 779 & 784 & 812 & 837 \\
\hline $\mathrm{MH}^{+}(\text {counts })^{\mathrm{b}}$ & $1.2 \times 10^{6}$ & $1.4 \times 10^{6}$ & $1.8 \times 10^{6}$ & $1.1 \times 10^{6}$ \\
\hline $\mathrm{H}_{3} \mathrm{O}^{+}(\text {counts })^{\mathrm{b}}$ & $1.5 \times 10^{3}$ & $2.8 \times 10^{4}$ & $6.6 \times 10^{3}$ & $1.5 \times 10^{4}$ \\
\hline$\left[\mathrm{MH}+\mathrm{H}_{2} \mathrm{O}\right]^{+}(\text {counts })^{\mathrm{b}}$ & $9.3 \times 10^{3}$ & - & $6.6 \times 10^{3}$ & $9.3 \times 10^{3}$ \\
\hline 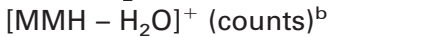 & - & - & $3.5 \times 10^{4}$ & - \\
\hline$[\mathrm{MMH}]^{+}(\text {counts })^{\mathrm{b}}$ & $1.2 \times 10^{4}$ & - & $1.4 \times 10^{4}$ & $3.4 \times 10^{5}$ \\
\hline Other significant product ions ${ }^{c}$ & & $m / z 77$ (9) & & $m / z 45(9)$ \\
\hline
\end{tabular}

aReference [15].

${ }^{b}$ Data were integrated over a period of $1 \mathrm{~min}$ at a repetition rate of $10 \mathrm{kHz}\left(6 \times 10^{5} \mathrm{scans}\right)$.

'Values in parentheses show percentage intensity relative to that of $\mathrm{MH}^{+}$.

tion (CID) technique in PTR ion trap mass spectrometry $[8,9]$ and the CI-MS technique that uses $\mathrm{O}_{2}^{+}$and $\mathrm{NO}^{+}$ as reagent ions $[10,11]$, both of which make use of fragment ions for the identification of isomeric VOCs.

\section{Experimental}

The instrument used in this study was a custom-built proton transfer reaction time-of-flight mass spectrome- ter (PTR-TOFMS). The details of the instrumental set-up have been described elsewhere $[12,13]$. In the two-stage mode, a reagent VOC $\left(\mathrm{VOC}_{1}\right)$ (acetonitrile, toluene, acetone, or diethyl ketone) was introduced from the port between the ED3 and ED4 electrodes (the $\mathrm{VOC}_{1}$ port), and the sample gas was introduced from the newly inserted port between the ED4 and ED5 electrodes (the sampling port). In the one-stage mode, in which the reagent ion was $\mathrm{H}_{3} \mathrm{O}^{+}$, nitrogen gas was

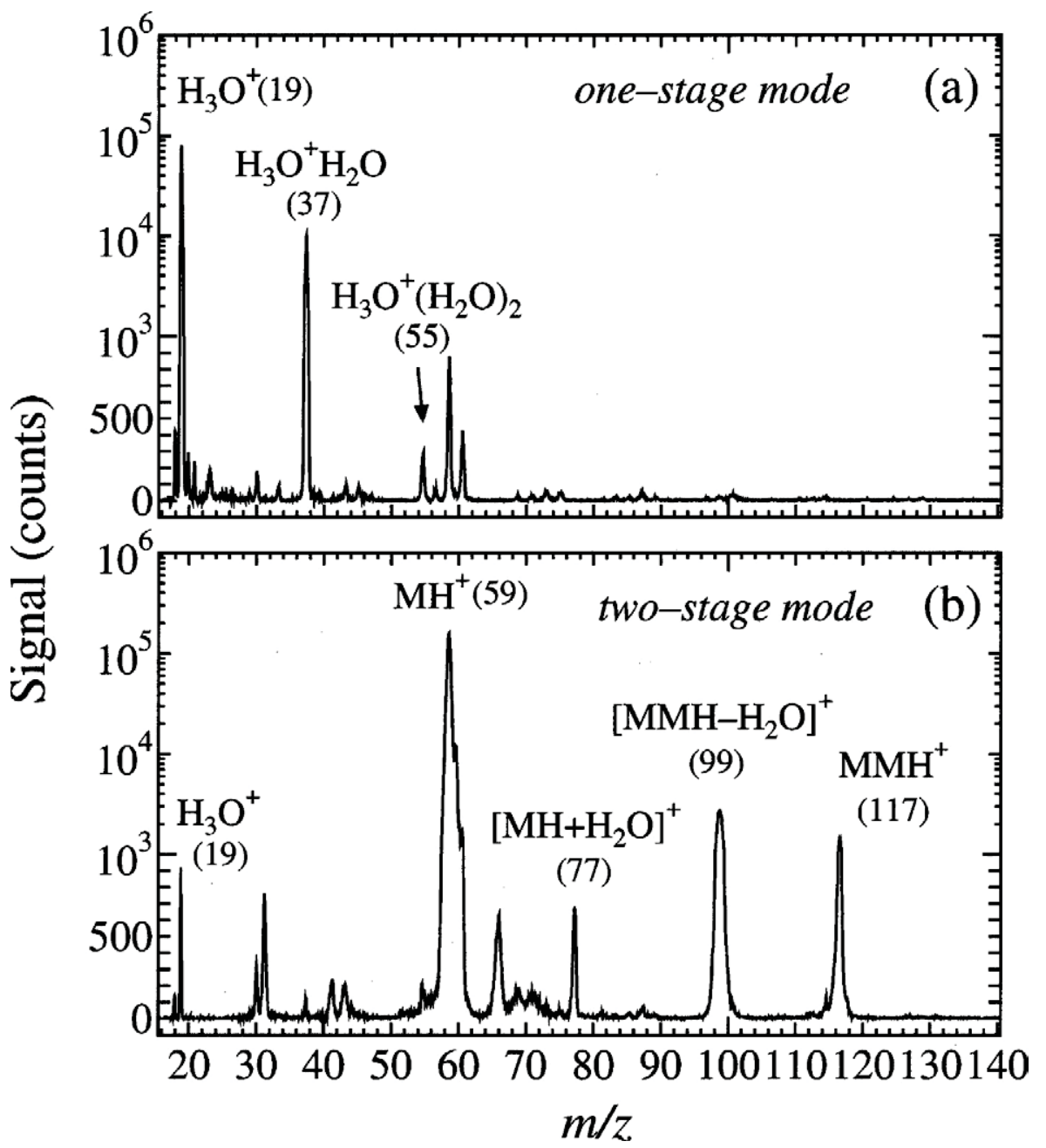

Figure 1. Background mass spectra obtained in the (a) one-stage mode and (b) two-stage mode with acetone as the reagent $\mathrm{VOC}_{1} \cdot \mathrm{M}=\left(\mathrm{CH}_{3}\right)_{2} \mathrm{CO}$. 
introduced from the $\mathrm{VOC}_{1}$ port by means of a threeway ball valve. Switching between the one-stage and two-stage modes did not affect the discharge between the ED1 and ED3 electrodes. The $\mathrm{VOC}_{1}$ reagents were introduced into the drift tube at pressures of $0.22,0.45$, 0.04 , and 0.15 mTorr for acetonitrile, toluene, acetone, and diethyl ketone, respectively. All experiments were carried out at a drift-tube field strength of $100 \mathrm{Td}$.

The gases and chemicals used were as follows: $\mathrm{N}_{2}$ (>99.99,995\%) and $\left(\mathrm{CH}_{3}\right)_{2} \mathrm{CO} /$ air $(0.0197 \%)$ from Japan Fine Products, Kawasaki, Japan; $\mathrm{CH}_{3} \mathrm{CN} / \mathrm{N}_{2}(0.104 \%)$, toluene $/ \mathrm{N}_{2}(0.0991 \%)$ and $\left(\mathrm{C}_{2} \mathrm{H}_{5}\right)_{2} \mathrm{CO} / \mathrm{N}_{2}(0.09,888 \%)$ from Takachiho, Tokyo, Japan; ethyl acetate (1.00 ppmv)/1,4dioxane (0.96 ppmv)/ $\mathrm{N}_{2}$ from Sumitomo Seika, Tokyo, Japan; and ethyl acetate $(>99.5 \%)$ and 1,4-dioxane (>99.0\%) from Wako Chemicals, Osaka, Japan.

To determine whether the isomer concentrations could be differentially and quantitatively obtained by the present technique, we prepared 50:50 mixtures of ethyl acetate and 1,4-dioxane in a bakeable and evacuable $6-\mathrm{m}^{3}$ photochemical chamber [14], and introduced the mixtures into the PTR-TOFMS instrument for analysis. Before each experiment, the photochemical chamber was filled with 800 torr of purified air. The reagents, ethyl acetate and 1,4-dioxane, were degassed by successive freeze-pump and thaw cycles, and the reagent vapors were collected in a calibrated glass bulb and then directed into the chamber with $\mathrm{N}_{2}$ as a carrier gas.
During the introduction of the samples, the air in the chamber was mixed with an internally located fan. The chamber wall was temperature controlled at $25^{\circ} \mathrm{C}$ $\left( \pm 1^{\circ} \mathrm{C}\right)$. The concentrations of ethyl acetate and 1,4dioxane in the chamber were monitored with an FT-IR spectrometer (Nicolet Nexus 670, Thermo, Walthan, MA) combined with a multireflection mirror system (optical path length $=221.5 \mathrm{~m}$ ) [14]. The spectral resolution was $1.0 \mathrm{~cm}^{-1}$. The peaks at $1759 \mathrm{~cm}^{-1}$ and $881 \mathrm{~cm}^{-1}$ were used for the determination of the concentrations of ethyl acetate and 1,4-dioxane, respectively. The precision of the FT-IR data were typically $0.5 \%$, and the detection limit for ethyl acetate and 1,4-dioxane was $\sim 4$ parts per billion by volume (ppbv) at a signal-to-noise ratio $(\mathrm{S} / \mathrm{N})$ of 2 .

\section{Results and Discussion}

The intensities of primary product ions obtained in the two-stage mode with acetonitrile, toluene, acetone, and diethyl ketone as reagents $\mathrm{VOC}_{1}$ are listed in Table 1. The intensity of $\mathrm{H}_{3} \mathrm{O}^{+}$in the one-stage mode was $6.5 \times 10^{5}$ counts for 1 min integration at a repetition of $10 \mathrm{kHz}$. For acetonitrile and acetone, the ion signal of $\mathrm{H}_{3} \mathrm{O}^{+}$at $m / z 19$ almost disappeared, and protonated acetonitrile $\left(\mathrm{CH}_{3} \mathrm{CN} \cdot \mathrm{H}^{+}\right)$and protonated acetone $\left(\left(\mathrm{CH}_{3}\right)_{2} \mathrm{CO} \cdot \mathrm{H}^{+}\right)$predominated. The intensities of the signals for these two species were approximately

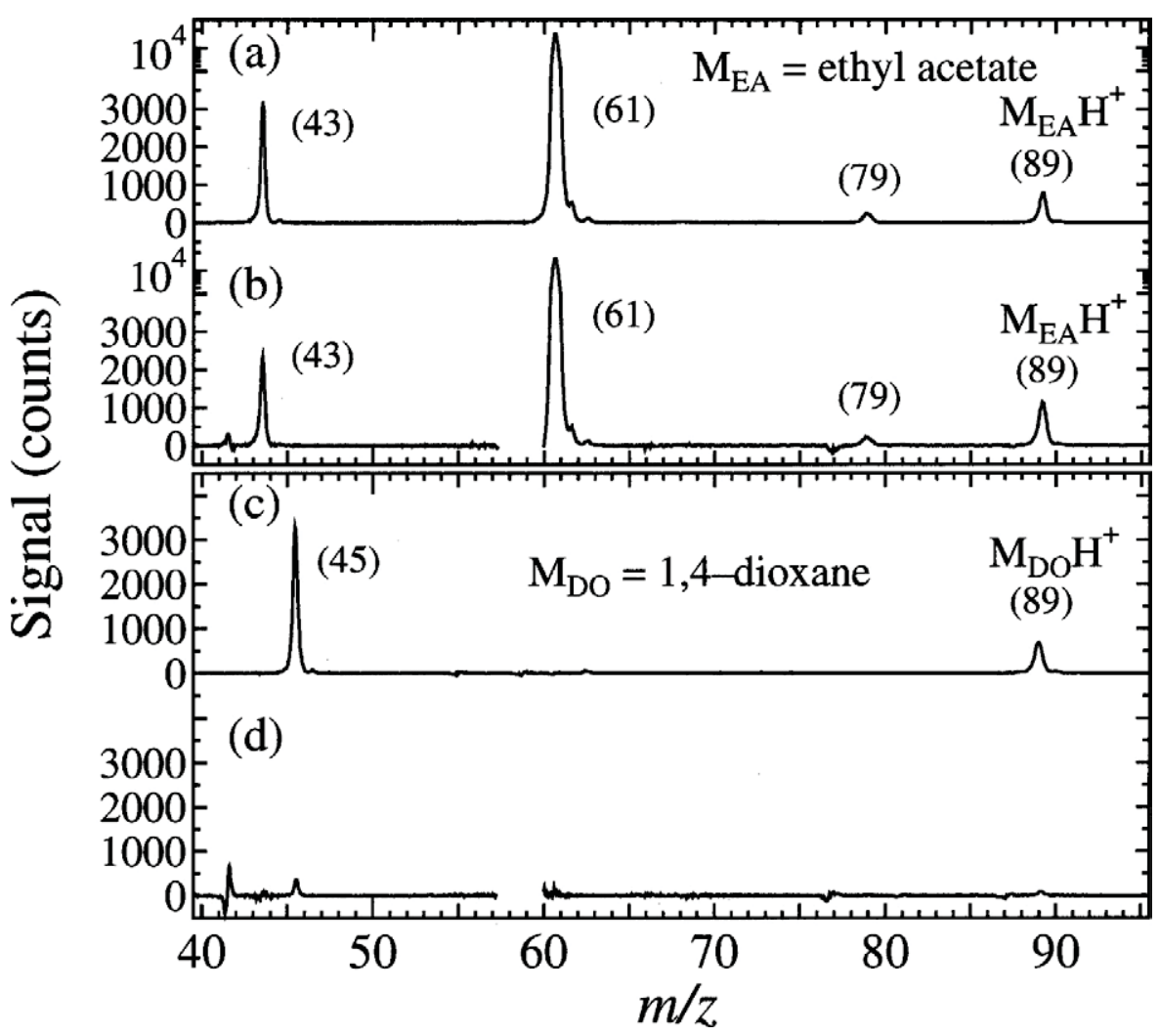

Figure 2. Mass spectra of ethyl acetate ( $\mathrm{M}_{\mathrm{EA}}$, mass 88$)$ and 1,4-dioxane $\left(\mathrm{M}_{\mathrm{DO}}\right.$, mass 88$)$ obtained in the one-stage mode (a) and (c), respectively, and the two-stage mode $(\mathbf{b})$ and $(\mathbf{d})$, respectively]. $\mathrm{VOC}_{1}=$ acetone. 
twice the intensity of the signal for $\mathrm{H}_{3} \mathrm{O}^{+}$, which is probably the result of the mass-dependent transmission efficiency of the TOFMS [13]. Background mass spectra obtained in the one-stage mode and the two-stage mode using acetone as the reagent $\mathrm{VOC}_{1}$ are shown in Figure 1a and $b$, respectively. In the two-stage mode, the ion signals of $\mathrm{H}_{3} \mathrm{O}^{+} \cdot\left(\mathrm{H}_{2} \mathrm{O}\right)_{n}=0,1,2$ at $\mathrm{m} / z$ 19, 37, and 55 almost disappeared, and a strong peak for protonated acetone, $\left(\mathrm{CH}_{3}\right)_{2} \mathrm{CO} \cdot \mathrm{H}^{+}$, was observed at $\mathrm{m} / z$ 59. The peak was broad because the relatively low mass resolution of our instrument, $m / \Delta m=\sim 100$, did not allow resolution of the isotopes. Small peaks assigned to $\left[\left(\mathrm{CH}_{3}\right)_{2} \mathrm{CO} \cdot \mathrm{H}+\mathrm{H}_{2} \mathrm{O}\right]^{+},\left[\left(\left(\mathrm{CH}_{3}\right)_{2} \mathrm{CO}\right)_{2} \cdot \mathrm{H}-\mathrm{H}_{2} \mathrm{O}\right]^{+}$, and $\left(\left(\mathrm{CH}_{3}\right)_{2} \mathrm{CO}\right)_{2} \cdot \mathrm{H}^{+}$were observed at $\mathrm{m} / \mathrm{z} 77,99$, and 117, respectively, with intensities of at most $2 \%$ of the intensity of $\left(\mathrm{CH}_{3}\right)_{2} \mathrm{CO} \cdot \mathrm{H}^{+}$.

In the case of toluene and diethyl ketone, strong ion signals of protonated molecules were observed, but the formation of fragment ions was also observed with very intense peaks at $m / z 77$ (probably $\mathrm{C}_{6} \mathrm{H}_{5}{ }^{+}$) and 45 (probably $\mathrm{C}_{2} \mathrm{H}_{5} \mathrm{O}^{+}$) (Table 1 ), respectively. In particular, the ion signal for $[\mathrm{MMH}]^{+}$was appreciable in the case of diethyl ketone because of its higher boiling point ( $375 \mathrm{~K}$ ) compared with the boiling points of other reagent VOCs (e.g., $329 \mathrm{~K}$ for acetone) [15]. These results suggested that of the VOCs examined in this study, acetonitrile and acetone were suitable for use as reagent VOCs.

Two isomeric VOCs of molecular weight 88, ethyl acetate $\left(\mathrm{CH}_{3} \mathrm{C}(\mathrm{O}) \mathrm{OC}_{2} \mathrm{H}_{5}\right)$ and 1,4-dioxane (cyclo$\mathrm{OCH}_{2} \mathrm{CH}_{2} \mathrm{OCH}_{2} \mathrm{CH}_{2}$ ), the PAs of which are 836 and 798 $\mathrm{kJ} \mathrm{mol}^{-1}$, respectively [15], were introduced as samples $\left(\mathrm{VOC}_{2}\right)$. Acetone was chosen as $\mathrm{VOC}_{1}$. The PA for ethyl acetate is higher than the PAs for $\mathrm{H}_{2} \mathrm{O}\left(691 \mathrm{~kJ} \mathrm{~mol}^{-1}\right)$ and acetone $\left(812 \mathrm{~kJ} \mathrm{~mol}^{-1}\right)$ [15], whereas the PA of 1,4-dioxane lies between the PAs of $\mathrm{H}_{2} \mathrm{O}$ and acetone. In the sample mass spectrum of ethyl acetate with the background mass spectrum subtracted in the onestage mode (Figure 2a), signals of protonated ethyl acetate and fragment ions assigned to $\mathrm{CH}_{3} \mathrm{CO}^{+}$, $\mathrm{CH}_{3} \mathrm{C}(\mathrm{O}) \mathrm{OH} \cdot \mathrm{H}^{+}$, and $\mathrm{CH}_{3} \mathrm{C}(\mathrm{O}) \mathrm{OH} \cdot \mathrm{H}_{3} \mathrm{O}^{+}$were observed at $m / z 89,43,61$, and 79 , respectively. A similar mass spectrum was obtained in the two-stage mode (Figure $2 b$ ). (Ion signals between $\mathrm{m} / \mathrm{z} 58$ and 60 were masked because they were scattered by subtraction of the background mass spectrum.) Signals for protonated 1,4dioxane and a fragment ion assigned as $\mathrm{C}_{2} \mathrm{H}_{5} \mathrm{O}^{+}$were observed at $m / z 89$ and 45 , respectively, in the one-stage mode (Figure 2c), but these signals were not observed in the two-stage mode (Figure $2 \mathrm{~d}$ ). These results clearly show that, as a result of the difference in the PAs of the

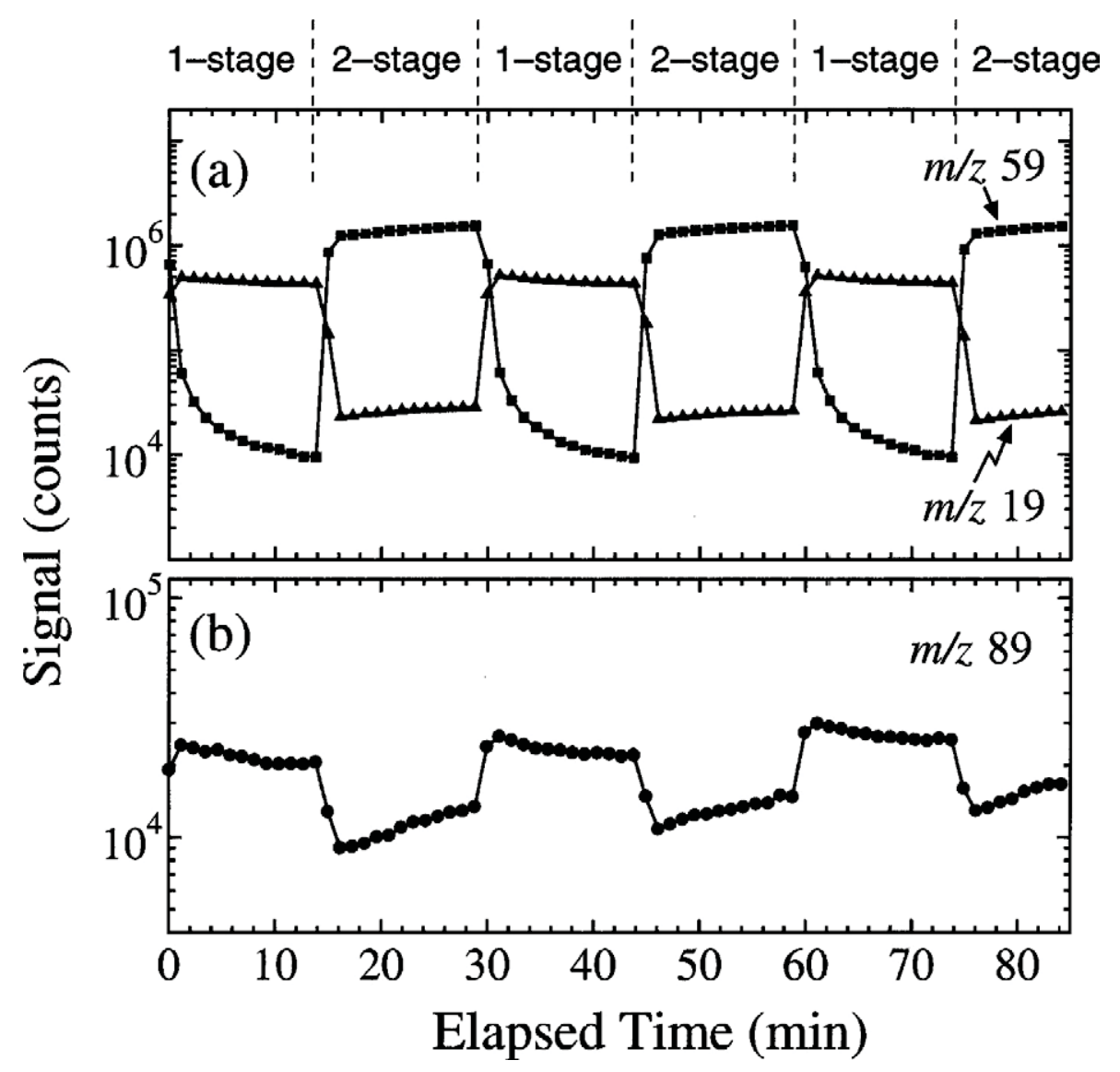

Figure 3. Temporal variations in the ion signals for (a) primary ions $\mathrm{H}_{3} \mathrm{O}^{+}(\mathrm{m} / z$ 19) and $\left(\mathrm{CH}_{3}\right)_{2} \mathrm{CO} \cdot \mathrm{H}^{+}(\mathrm{m} / z$ 59) and $(\mathbf{b})$ product ions at $\mathrm{m} / \mathrm{z} 89$ from a mixture of ethyl acetate and 1,4-dioxane, obtained by switching between operating modes. $\mathrm{VOC}_{1}=$ acetone. 
Table 2. Normalized signal Intensities obtained in one-stage and two-stage modes for 50:50 mixtures of ethyl acetate and 1,4-dioxane

\begin{tabular}{lccc}
\hline [Ethyl acetate] $(\mathrm{ppmv})$ & {$[1,4-$ Dioxane] $(\mathrm{ppmv})$} & $I_{\text {one-stage }}\left(10^{3} \mathrm{ncounts}^{\mathrm{a}, \mathrm{c}}\right.$ & $I_{\text {two-stage }}\left(10^{3} \mathrm{ncounts}\right)^{\mathrm{b}, \mathrm{c}}$ \\
\hline \hline Cylinder & 0.96 & $45.9 \pm 1.5$ & $8.6 \pm 0.6$ \\
$\quad 1.00$ & & & \\
Chamber (FT-IR) ${ }^{\mathrm{d}}$ & 1.00 & $49.2 \pm 2.2$ & $8.7 \pm 0.9$ \\
$\quad 0.97$ & 0.66 & $29.6 \pm 0.3$ & $5.1 \pm 0.3$ \\
0.63 & 0.33 & $14.4 \pm 0.9$ & $2.5 \pm 0.3$ \\
0.32 & 0.3 & \\
\hline
\end{tabular}

a Signal intensities at $\mathrm{m} / \mathrm{z} 89$ obtained in one-stage mode normalized to $10^{6}$ counts of $\mathrm{H}_{3} \mathrm{O}^{+}$.

bSignal intensities at $\mathrm{m} / \mathrm{z} 89$ obtained in two-stage mode normalized to $10^{6}$ counts of $\left(\mathrm{CH}_{3}\right)_{2} \mathrm{CO} \cdot \mathrm{H}^{+}$. VOC ${ }_{1}=$ acetone.

${ }^{c}$ Error bars represent $95 \%$ confidence levels by $t$-test.

dExperiments with each compound alone were performed, and the following results were obtained: $I_{\text {one-stage }}=(14.8 \pm 0.6) \times 10^{3}$ ncounts and $I_{\text {two-stage }}=(8.2 \pm 0.7) \times 10^{3}$ ncounts for $0.97 \mathrm{ppmv}$ of ethyl acetate; and $I_{\text {one-stage }}=(32.3 \pm 2.8) \times 10^{3}$ ncounts and $I_{\text {two-stage }}=(0.2 \pm 0.4) \times 10^{3}$ ncounts for 0.98 ppmv of 1,4-dioxane.

two VOC $_{2}$ samples, a second PTR ionization occurred for ethyl acetate but not for 1,4-dioxane.

Figure 3a shows the temporal variations in the primary ions $\mathrm{H}_{3} \mathrm{O}^{+}\left(\mathrm{m} / \mathrm{z}\right.$ 19) and $\left(\mathrm{CH}_{3}\right)_{2} \mathrm{CO} \cdot \mathrm{H}^{+}(\mathrm{m} / \mathrm{z} 59)$ obtained when the two modes were switched at $\sim 15$-min intervals. When we changed the operating mode from the onestage mode to the two-stage mode at $\sim 15$ min intervals, the ion signals of $\mathrm{H}_{3} \mathrm{O}^{+}(\mathrm{m} / \mathrm{z} 19)$ decreased rapidly, and those of $\left(\mathrm{CH}_{3}\right)_{2} \mathrm{CO} \cdot \mathrm{H}^{+}(\mathrm{m} / \mathrm{z} 59)$ increased rapidly. However, when the operating mode was switched from the two-stage mode to the one-stage mode, ion signals of $\left(\mathrm{CH}_{3}\right)_{2} \mathrm{CO} \cdot \mathrm{H}^{+}$decreased slowly, probably because acetone remained on the surface of the drift tube or the gas line or both. Figure $3 \mathrm{~b}$ shows the temporal profile of ion signals at $\mathrm{m} / \mathrm{z} 89$ when a 50:50 mixture of ethyl acetate and 1,4-dioxane prepared in a cylinder was added (the concentration of each compound was $1.0 \mathrm{ppmv}$ ). When the mode was switched, the ion intensity changed markedly. In the one-stage mode, the intensity was high, and both ethyl acetate and 1,4-dioxane were detected, whereas in the two-stage mode, the intensity was low, and only ethyl acetate was detected.

The 50:50 mixtures of ethyl acetate and 1,4-dioxane at three concentrations $(\sim 1.0,0.66$, and $0.33 \mathrm{ppmv})$ were prepared in a $6 \mathrm{~m}^{3}$ photochemical chamber and were introduced into the PTR-TOFMS instrument. The normalized signal intensities obtained in the one-stage and two-stage modes are listed in Table 2 . By using the values of $(45.9 \pm 1.5) \times 10^{3}$ ncounts for the one-stage mode $\left(S_{\text {one-stage }}\right)$ and $(8.6 \pm 0.6) \times 10^{3}$ ncounts for the two-stage mode $\left(S_{\text {two-stage }}\right)$, obtained from the cylinder of the 50:50 mixture of ethyl acetate and 1,4-dioxane, we determined the mixing ratios of ethyl acetate in the chamber by means eq 3 :

$$
\text { [ethyl acetate }](\mathrm{ppmv})=I_{\text {two-stage }} / S_{\text {two-stage }}
$$

And the mixing ratios of 1,4-dioxane were obtained from eq 4 :

$$
\begin{aligned}
{[1,4-\text { dioxane }](\mathrm{ppmv})=} & I_{\text {one-stage }} / S_{\text {one-stage }} \\
& -[\text { ethyl acetate }]
\end{aligned}
$$

The ethyl acetate and 1,4-dioxane concentrations determined from the two-stage PTR-TOFMS were compared with those obtained by FT-IR (Figure 4). Note that the concentrations for both ethyl acetate and 1,4dioxane were determined independently; PTR-TOFMS was based on gravimetrically prepared gas standards, and FT-IR was based on absorption photometry. These results generally agreed within their measurement uncertainties, which suggest that by switching the reagent ions, we can differentiate isomeric VOCs by means of the mass signals of their protonated molecules.

This method could also be used to differentiate ion signals when the signal for a fragment ion overlaps with that for a protonated molecule. For example, in the mass spectrum of ethyl benzene $\left(\mathrm{PA}=788 \mathrm{~kJ} \mathrm{~mol}^{-1}\right.$ [15]) in the one-stage mode (Figure 5a), in addition to a large peak of protonated molecules at $\mathrm{m} / \mathrm{z} 107$, a small fragment peak was observed at $\mathrm{m} / \mathrm{z} 79$, and the intensity

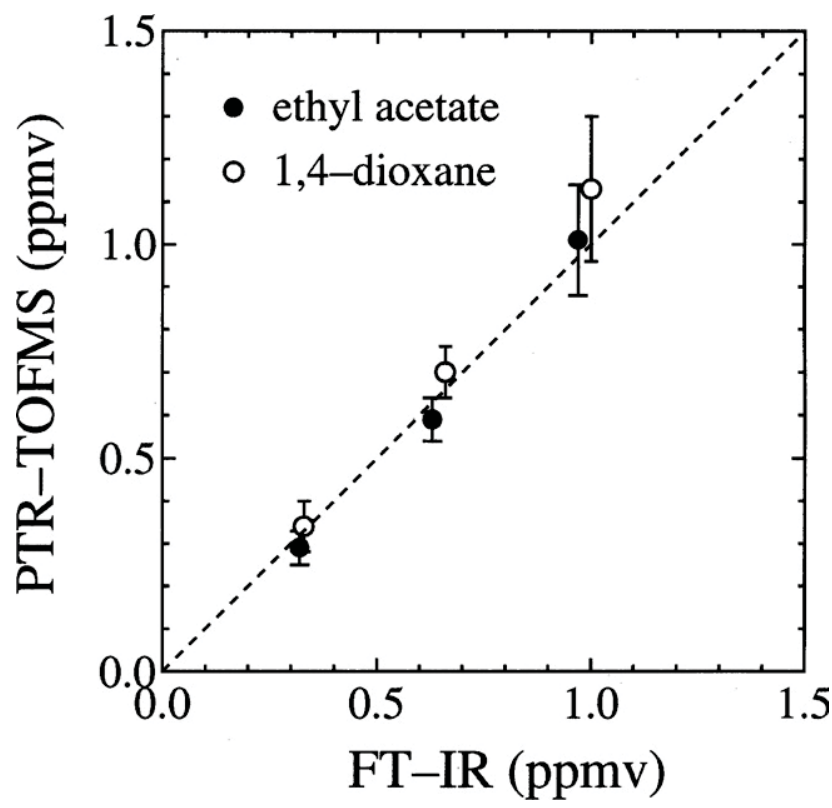

Figure 4. Comparison of ethyl acetate and 1,4-dioxane concentrations determined by two-stage PTR with those obtained by FTIR. The dashed line represents an $x=y$ line. $\mathrm{VOC}_{1}=$ acetone. 


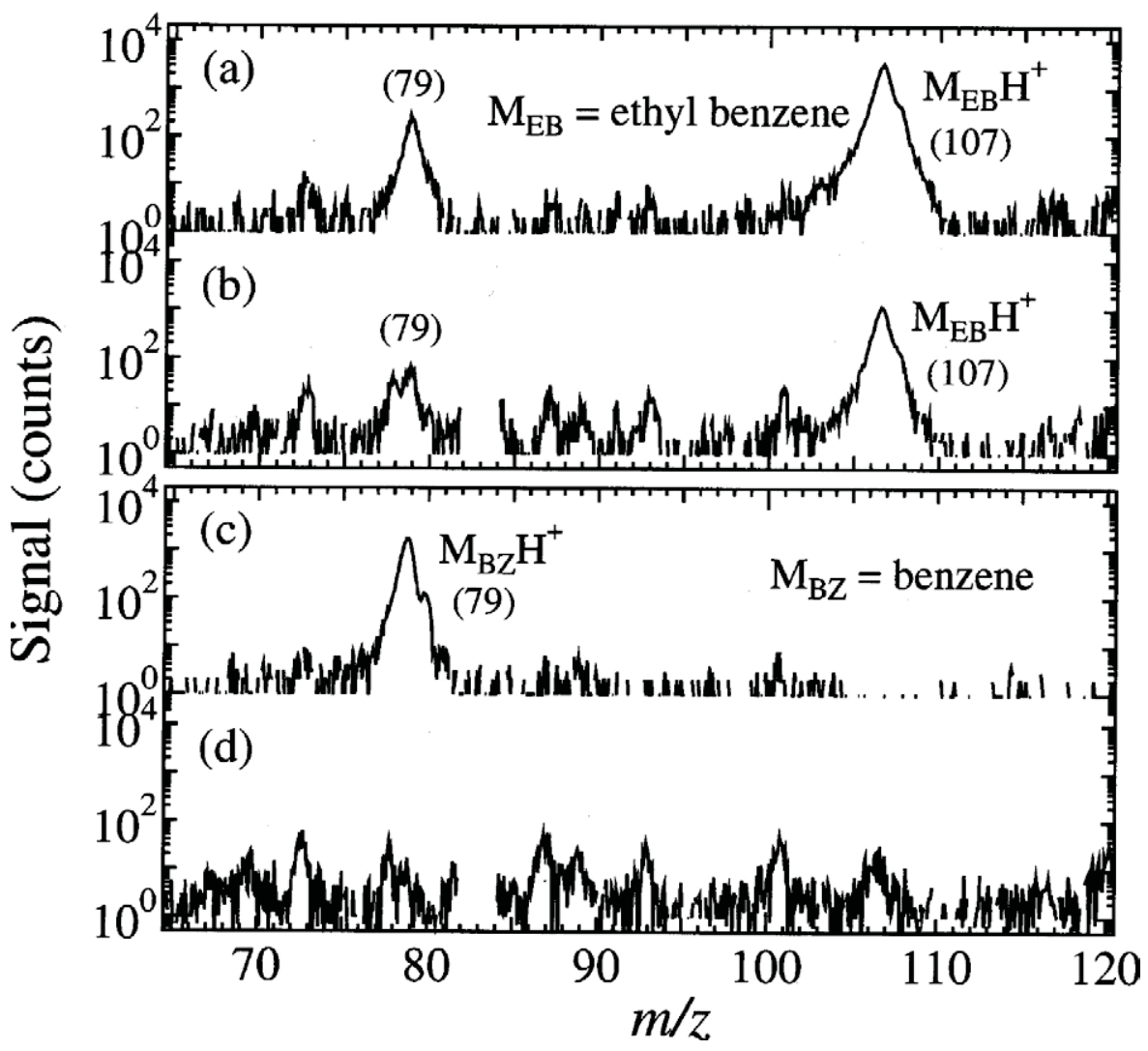

Figure 5. Mass spectra of ethyl benzene $\left(\mathrm{M}_{\mathrm{EB}}\right.$, mass 106) and benzene ( $\mathrm{M}_{\mathrm{BZ}}$, mass 78$)$ obtained in the one-stage mode ((a) and (c), respectively), and the two-stage mode $\left((\mathbf{b})\right.$ and $(\mathbf{d})$, respectively). $\mathrm{VOC}_{1}$ $=$ acetonitrile.

of this peak was 0.07 relative to that at $m / z 107$. In the two-stage mode with acetonitrile as a reagent VOC, a similar mass spectrum was observed, although the total ion counts were reduced by approximately half (Figure $5 b)$. The intensity of the ion signal at $m / z 79$ was 0.05 relative to that at $m / z$ 107. The mass spectrum of benzene $\left(\mathrm{PA}=750 \mathrm{~kJ} \mathrm{~mol}^{-1}[15]\right)$ in the one-stage mode (Figure $5 \mathrm{c}$ ) showed a single peak for the protonated molecule at $m / z 79$. In contrast to the result for ethyl benzene (Figure $5 b$ ), the peak at $m / z 79$ disappeared for benzene in the two-stage mode (Figure $5 \mathrm{~d}$ ). These results suggest that the use of $\mathrm{CH}_{3} \mathrm{CN} \cdot \mathrm{H}^{+}$as a reagent ion would allow us to distinguish benzene from alkyl benzenes that produce fragment ions at $m / z 79$ [3, 16-19] and would prevent possible overestimation of benzene concentrations in samples in which the relative abundances of benzene and alkyl benzenes are unknown.

\section{Conclusions}

A two-stage PTR ionization source was developed to generate reagent ions other than $\mathrm{H}_{3} \mathrm{O}^{+}$, and the feasibility of the source for selectively detecting VOCs was examined. We tested protonation reactions of $\mathrm{H}_{3} \mathrm{O}^{+}$ with acetone and acetonitrile and found that both reagents gave a single strong peak, which corresponded to the protonated target VOCs. By switching reagent ions between $\mathrm{H}_{3} \mathrm{O}^{+}$and the designated $\mathrm{VOC}_{1} \cdot \mathrm{H}^{+}$, we could differentiate isomeric VOCs with the same molecular weight but different PAs by monitoring the ion signals of their protonated molecules. This two-stage PTR ionization approach may be applicable to other isomeric species including aldehydes and ketones if the appropriate reagent ions for those pairs are selected.

\section{Acknowledgments}

The authors are grateful to Jun Hirokawa (Hokkaido University) for his valuable comments and discussion of methods for the production of reagent ions. They acknowledge Kei Sato and Takashi Imamura for their help with the chamber experiments. They acknowledge financial support for this work by the Ministry of the Environment through the Environmental Technology Development Fund (FY 2004-2005), by the Steel Industry Foundation for the Advancement of Environmental Protection Technology (FY2005-2006), and by Asahi Breweries Foundation (FY2007).

\section{References}

1. Lindinger, W: Hansel, A.; Jordan, A. Proton-Transfer-Reaction Mass Spectrometry (PTR-MS): On-Line Monitoring of Volatile Organic Compounds at pptv Levels. Chem. Soc. Rev. 1998, 27, 347-354.

2. Lindinger, W.; Hansel, A.; Jordan, A. On-Line Monitoring of Volatile Organic Compounds at pptv Levels by Means of Proton-TransferReaction Mass Spectrometry (PTR-MS): Medical Applications, Food 
Control and Environmental Research. Int. J. Mass Spectrom Ion Processes 1998, 173, 191-241.

3. de Gouw, J.; Warneke, C. Measurements of Volatile Organic Compounds in the Earth's Atmosphere Using Proton-Transfer-Reaction Mass Spectrometry. Mass Spectrom. Rev. 2007, 26, 223-257.

4. Munson, M. S. B.; Field, F. H. Chemical Ionization Mass Spectrometry. I. General Introduction. J. Am. Chem. Soc. 1966, 88, 2621-2630.

5. Nowak, J. B.; Huey, L. G.; Eisele, F. L.; Tanner, D. J.; Mauldin, R. L., III; Cantrell, C.; Kosciuch, E.; Davis, D. D. Chemical Ionization Mass Spectrometry Technique for Detection of Dimethylsulfoxide and Ammonia. J. Geophys. Res. 2002, 107, 4363, doi:10.1029/2001JD001058.

6. Fehsenfeld, F. C.; Huey, L. G.; Leibrock, E.; Dissly, R.; Williams, E.; Ryerson, T. B.; Norton, R.; Sueper, D. T.; Hartsell, B. Results from an Informal Intercomparison of Ammonia Measurement Techniques. J. Geophys. Res. 2002, 107, 4812, doi:10.1029/2001JD001327.

7. Nowak, J. B.; Huey, L. G.; Russell, A. G.; Tian, D.; Neuman, J. A.; Orsini, D.; Sjostedt, S. J.; Sullivan, A. P.; Tanner, D. J.; Weber, R. J.; Nenes, A.; Edgerton, E.; Fehsenfeld, F. C. Analysis of Urban Gas Phase Ammonia Measurements from the 2002 Atlanta Aerosol Nucleation and RealTime Characterization Experiment (ANARChE). J. Geophys. Res. 2006, 111, D17308, doi:10.1029/2006JD007113.

8. Prazeller, P.; Palmer, P.T.; Boscaini, E.; Jobson, T.; Alexander, M. Proton Transfer Reaction Ion Trap Mass Spectrometry. Rapid Commun. Mass Spectrom. 2003, 17, 1593-1599.

9. Warneke, C.; de Gouw, J. A.; Lovejoy, E. R.; Murphy, P. C.; Kuster, W. C.; Fall, R. Development of Proton-Transfer Ion Trap-Mass Spectrometry: On-Line Detection and Identification of Volatile Organic Compounds in Air. J. Am. Soc. Mass Spectrom. 2005, 16, 1316-1324.

10. Wyche, K. P.; Blake, R. S.; Willis, K. A.; Monks, P. S.; Ellis, A. M. Differentiation of Isobaric Compounds Using Chemical Ionization Reaction Mass Spectrometry. Rapid Commun. Mass Spectrom. 2005, 19, 3356-3362.

11. Blake, R. S.; Wyche, K. P.; Ellis, A. M.; Monks, P. S. Chemical Ionization Reaction Time-of-Flight Mass Spectrometry: Multi-Reagent Analysis for
Determination of Trace Gas Composition. Int. J. Mass Spectrom. 2006, 254, 85-93.

12. Inomata, S.; Tanimoto, H.; Aoki, N.; Hirokawa, J.; Sadanaga, Y. A Nove Discharge Source of Hydronium Ions for Proton Transfer Reaction Ionization: Design, Characterization, and Performance. Rapid Commun. Mass Spectrom. 2006, 20, 1025-1029.

13. Tanimoto, H.; Aoki, N.; Inomata, S.; Hirokawa, I.; Sadanaga, Y. Development of a PTR-TOFMS Instruments for Real-Time Measurements of Volatile Organic Compounds in air. Int. J. Mass Spectrom. 2007, 263, $1-11$.

14. Sato, K.; Klotz, B.; Hatakeyama, S.; Imamura, T.; Washizu, Y.; Matsumi, Y.; Washida, N. Secondary Organic Aerosol Formation During the Photo-Oxidation of Toluene: Dependence on Initial Hydrocarbon Concentration. Bull. Chem. Soc. Jpn. 2004, 77, 667-671.

15. NIST Chemistry WebBook, NIST Standard Reference Database Number 69; Mallard, W. G., Ed.; National Institute of Standards and Technology: Gaithersburg, MD, 2005; http:/ / webbook.nist.gov.

16. Warneke, C.; de Gouw, J.; Kuster, W. C.; Goldan, P.; Fall, R. Validation of Atmospheric VOC Measurement by Proton-Transfer-Reaction Mass Spectrometry Using a Gas-Chromatographic Preseparation Method. Environ. Sci. Technol. 2003, 37, 2494-2501.

17. Midey, A. J.; Williams, S.; Arnold, S. T.; Viggiano, A. A. Reactions of $\mathrm{H}_{3} \mathrm{O}^{+}\left(\mathrm{H}_{2} \mathrm{O}\right)_{0,1}$ with Alkylbenzenes from 298 to 1200 K. J. Phys. Chem. A 2002, 106, 11726-11738.

18. Jobson, B. T.; Alexander, M. L.; Maupin, G. D.; Muntean, G. G. On-Line Analysis of Organic Compounds in Diesel Exhaust Using a Proton Transfer Reaction Mass Spectrometry (PTR-MS). Int. J. Mass Spectrom. 2005, 245, 78-89.

19. Rogers, T. M.; Grimsrud, E. P.; Herndon, S. C.; Jayne, J. T.; Kolb, C. E.; Allwine, E.; Westberg, H.; Lamb, B. K.; Zavala, M.; Molina, L. T. Molina, M. J.; Kinghton, W. B. On-Road Measurements of Volatile Organic Compounds in the Mexico City Metropolitan Area Using Proton Transfer Reaction Mass Spectrometry. Int. J. Mass Spectrom. 2006, 252, 26-37. 